\title{
FAKTOR HIDAYAH DALAM DAKWAH
}

\author{
Kamaluddin \\ Fakultas Dakwah dan Ilmu Komunikasi IAIN Padangsidimpuan, \\ (E-mail: kamal.ritonga65@gmail.com)
}

\begin{abstract}
Hidayah consists of four kinds, that is first hidayah instinct, senses of mind and fitrah. Both guidance dalalah wal irsyad, namely the direction of religious science in the form of invitation, guidance and education. Hidayah this is the duty of the Prophet and da'i. The three guidance of taufik or ma'unah, ie, faith and Islam are inspired to the human heart. The four hidayah heaven received later in the day. Prophet and da'i can only give guidance in the form of wal-irshad in the form of invite, guide and teach people about aqidah, pikih, law and morals, while taufik hidayah ma'unah in the form of faith and piety, only God can give it because $\mathrm{He}$ is who knows who is heretical and who is entitled to guidance. The prophet and da'i are not entitled to give the guidance of this ma'unah to man, even to his own loved ones who loved and loved. To obtain the ma'unah guidance, preachers let guiding mad'unya so tauhid, pious charity, sole trust, pray and stay away from polytheism and hypocrisy.
\end{abstract}

Keyword: Hidayah, Da'wah.

\begin{abstract}
Abstrak
Hidayah terdiri dari jenis emapat, yaitu insting hidayah pertama, indera pikiran dan fitrah. Kedua pedoman dalalah wal irsyad, yaitu arah ilmu agama dalam bentuk undangan, bimbingan dan pendidikan. Hidayah ini adalah tugas Nabi dan da'i. Tiga pedoman taufik atau ma'unah, yaitu, iman dan Islam diilhami oleh hati manusia. Empat surga hidayah diterima kemudian pada hari itu. Nabi dan da'i hanya dapat memberikan bimbingan dalam bentuk wal-irshad dalam bentuk mengundang, membimbing dan mengajar orang-orang tentang aqidah, pikih, hukum dan moral, sedangkan taufik hidayah ma'unah dalam bentuk keimanan dan takwa, hanya Tuhan dapat memberikannya karena Dialah yang tahu siapa yang sesat dan siapa yang berhak atas bimbingan. Nabi dan da'i tidak berhak untuk memberikan bimbingan ma'unah ini kepada manusia, bahkan kepada orangorang yang dikasihinya yang mencintai dan mencintai. Untuk mendapatkan bimbingan ma'unah, para pengkhotbah membiarkan membimbing mad'unya sehingga tauhid, amal saleh, satu-satunya kepercayaan, berdoa dan jauhi politeisme dan kemunafikan.
\end{abstract}




\section{A. Pendahuluan}

Keberhasilan dakwah dipengaruhi oleh dua faktor utama, yaitu faktor usaha (muktasabiy) dan faktor hidayah (tawqify). Faktor usaha terkait dengan beberapa dimensi dakwah seperti da'i, mad'u, metode, materi, media, tujuan dan lingkungan dakwah. Sedangkan faktor hidayah adalah taufiq yang diberikan Allah kepada mad'u berupa keimanan dan ketakwaan kepada Allah swt. Kedua faktor tersebut saling terkait anatara satu sama lain dalam mencapai kesuksesan dakwah. Para nabi Allah dalam mengemban tugas-tugas dakwahnya berusaha memberikan petunjuk kepada masyarakat melalui ajaran-ajaran yang diwahyukan Allah kepada mereka untuk disampaikan kepada ummat manusia. Diantaranya adalah berupa ajaran tauhid, fikih, akhlak serta sejarah ummat terdahulu. Para nabi mengajak manusia kepada akidah Islamiyah, mendirikan ibadah serta berakhlak mulia dalam kehidupannya.

Masyarakat mad'u terdiri dari kelompok manusia non muslim dan kelompok yang sudah muslim. Bagi kelompok non muslim, dakwah ditujukan untuk mengajak dan menyeru mereka supaya beriman kepada Allah serta mengamalkan syari'ah-Nya. Bagi yang sudah muslim, dakwah dimaksudkan seagai peningkatan keimanan dan ketakwaan kepada Allah swt. Oleh karena itu, dakwah Islam menjadi tugas dan tanggung jawab para nabi dan rasul serta kewajiban bagi seluruh ummat Islam pada umumnya serta para ulama pada khususnya. Para da'i dalam melaksanakan tugas dan kewajibannya menyeru manusia kepada Islam tidak terlepas dari adanya faktor usaha dan faktor hidayah dan taufik dari Allah swt. Keberhasilannya tidak tergantung hanya kepada usaha dan petunjuk para da'i, tetapi juga terkait dengan faktor hidayah berupa inayah dan taufik Allah swt.

Para da'i tidak bisa mempengaruhi mad'unya supaya mengikuti seruan dakwah selain dari mengajak dan menyampaikan ajaran-ajaran Islam. Da'i tidak dapat secara mutlak mempengaruhi mad'u tanpa faktor hidayah dari Allah swt. walaupun orang yang sangat dikasihi dan dicintai para da'i. Firman Allah dalam surat al-Qashash (28) ayat 56.

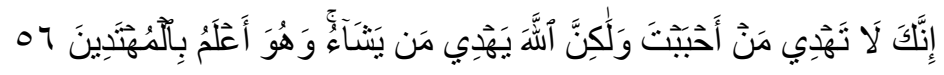


"Sesungguhnya kamu tidak akan dapat memberi petunjuk kepada orang yang kamu kasihi, tetapi Allah memberi petunjuk kepada orang yang dikehendaki-Nya, dan Allah lebih mengetahui orang-orang yang mau menerima petunjuk". ${ }^{1}$

Sebab turunnya ayat ini berkaitan dengan meninggalnya Abu Thalib dalam keadaan tetap memeluk agama Abdul Muththalib (musyrik). Hal ini sebagaimana ditunjukkan hadits yang diriwayatkan dalam Shahih Al Bukhari dan Shahih Muslim, dari Ibnu Al Musayyab, bahwa bapaknya (Al Musayyab) berkata: 'Tatkala Abu Thalib akan meninggal, Rasulullah SAW. bergegas mendatanginya. Dan saat itu, 'Abdullah bin Abu Umayyah serta Abu Jahal berada di sisinya. Beliau Shallallahu 'alaihi wa sallam berkata kepadanya: "Wahai, pamanku. Ucapkanlah la ilaha illallah; suatu kalimat yang dapat aku jadikan pembelaan untukmu di hadapan Allah,'. Akan tetapi, ‘Abdullah bin Abu Umayyah dan Abu Jahal menimpali dengan ucapan : 'Apakah engkau (Abu Thalib) membenci agama Abdul Muththalib?'. Lalu Nabi SAW. mengulangi sabdanya lagi. Namun mereka berdua pun mengulang kata-katanya itu. Maka akhir kata yang diucapkannya, bahwa dia masih tetap di atas agama Abdul Muthalib dan enggan mengucapkan La ilaha illallah. Kemudian Nabi SAW. bersabda: "Sungguh, akan aku mintakan ampunan untukmu, selama aku tidak dilarang”. Lalu Allah menurunkan firmanNya dalam surat at-Taubah (9) ayat $113 .^{2}$



"Tiadalah sepatutnya bagi Nabi dan orang-orang yang beriman memintakan ampun (kepada Allah) bagi orang-orang musyrik, walaupun orang-orang musyrik itu adalah kaum Kerabat (Nya), sesudah jelas bagi mereka, bahwasanya orang-orang musyrik itu adalah penghuni neraka jahanam". 3

\footnotetext{
${ }^{1}$ Departemen Agama RI, Al-Qur'an Dan Terjemahnya, (Jakarta: CV. Diponegoro, 2005) h. 313.

${ }^{2}$ Syaikh Abdurrahman bin Hasan Alu, Fathul Majid, Syarh Kitab At Tauhid, (Mesir: Dar Maktabah tt.) h. 210. Ibnu Katsir mengemukakan bahwa dalam riwayat Ibu Mas'ud sebab turun surat at-Taubah ayat 113 ini ialah ketika nabi SAW dibolehkan berziarah ke makam ibunya Aminah, tetapi dengan turunnya ayat ini, maka nabi tidak diizinkan mendo'akannya karena masih dalam kemusyrikan. Tafsir Al-Qur'anul Karim, (Beirut: Dar al-Fikri), 1985

${ }^{3}$ Departemen Agama RI. Al-Qur'an Dan Terjemahnya, (Jakarta: CV. Diponegoro, 2005) h. 163.
} 
Terjadinya kasus-kasus konversi agama dikalangan ummat beragama tidak terlepas dari adanya faktor-faktor intern dan ekstren individu atau golongan. Selain itu terdapat juga faktor hidayah atau petunjuk Allah yang mempengaruhinya. Konversi agama dapat terjadi bagi ummat Islam lalu berpindah keyakinan kepada agama lain, dan sebaliknya dari kelompok non muslim beralih keyakinan menjadi ummat Islam.

Pengertian konversi agama menurut etimologi; konversi berasal dari kata latin "conversio" yang berarti tobat pindah, berubah (agama). Selanjutnya kata tersebut dipakai dalam kata Inggris “conversion” yang mengandung pengertian: berubah dari suatu keadaan, atau dari suatu agama ke agama lain (change from one state, or from one religion, to another). Berdasarkan arti kata-kata tersebut dapat diketahui bahwa konversi agama mengandung pengertian: bertobat, berubah agama, berbalik pendirian (berlawanan arah) terhadap ajaran agama atau masuk ke dalam agama. Di samping faktor di atas, konversi agama juga didorong oleh beberapa faktor sesuai dengan perspektif pandang keahlian masing masing:

1. Petunjuk ilahi. Petunjuk Ilahi disebut dengan hidayah. Dalam konteks ini, pengaruh supernatural berperan secara dominan dalam proses terjadinya konversi agama pada diri seseorang atau kelompok. Faktor ini direkomendasikan oleh para ahli agama atau teolog.

2. Pengaruh sosial. Faktor ini direkomendasikan oleh pasa sosiolog. Pengaruh sosial yang mendorong terjadinya konversi agama.

3. Faktor psikologis yang ditimbulkan oleh faktor intern maupun faktor ekstern. Faktor ini direkomendasikan oleh para psikolog. Faktor ini apabila mempengaruhi seseorang atau kelompok akan menimbulkan semacam gejala tekanan batin, lalu akan terdorong untuk mencari jalan keluar yaitu ketenangan batin. Dalam kondisi jiwa yang demikian itu secara psikologis kehidupan seseorang itu menjadi kosong dan tak berdaya sehingga ia mencari perlindungan kekuatan lain yang mampu memberikan ketenangan jiwa. ${ }^{4}$

Uraian di atas menunjukkan bahwa keberhasilan dakwah baik dimaksudkan sebagai ajakan kepada agama Islam atau sebagai upaya intensifikasi

\footnotetext{
${ }^{4}$ Thouless, Pengantar Psikologi Agama, (Jakarta: Raja Grafindo Persada, 2000) h. 201.
} 
pengamalan agama bagi kaum muslimin, tidak terlepas dari beberapa faktor, dan faktor hidayah menjadi faktor utama keberhasilan dakwah. Dakwah sebagai salah satu sarana penyiaran Islam menjadi kewajiban ummat Islam yang tidak luput dari berbagai tantangan dan kegagalan, baik dakwah itu ditujukan kepada mad'u non muslim, maupun kepada yang sudah muslim. Respon masyarakat terhadap dakwah antara lain terdiri dari kelompok yang menerima dengan segera, ada yang berpura-pura menerima dan ada kelompok yang menolak dan bahkan menentang dan menghalangi dakwah. Dalam beberapa kasus conversi agama ternyata ada mad'u yang sangat diharapkan masuk Islam tetapi tidak bisa, sebaliknya ada orang yang di luar dugaan, ternyata mengalami conversi ke dalam Islam. Oleh karena itu apakah bagaimanakah faktor hidayah itu dalam proses dakwah dan bagaimana upaya yang dapat dilakukan da'i dalam mencapai keberhasilan dakwah.?

\section{B. Landasan Teoritis}

\section{Karakteristik Da'i dan Mad'u}

Komponen dakwah terdiri dari da'i, mad'u, materi, metode, tujuan, media dan efek dakwah. Tujuh komponen ini merupakan unsur-unsur yang saling terkait antara satu sama lain dalam poroses aktivitas dakwah. Setiap unsur memiliki peran dalam aktivitas yang diembannya pada tahapan-tahapan yang berlangsung dengan prinsif-prinsif utama kegiatan dakwah dalam pencapaian tujuan yang telah ditetapkan. Unsur Da'i dan mad'u menjadi subjek dan objek dakwah yang berafiliasi satu sama lain melalui aspek kognitif, afektif dan psikomotor yang melibatkan pengaruh-pengaruh psikologis, sosiologis, antropologis dengan memanfaatkan komunikasi sebagai media.

Berdasarkan pengertian kata dakwah secara etimilogi, yaitu mengajak, menyeru, mengundang, memintak, memohon atau berdo'a, maka kata dakwah termasuk fi'il muta'addiy yakni $d a^{\prime} a$ - yad'u - da'watan, berarti fi'il yang membutuhkan objek (kata kerja transitif). Ini menujukkan bahwa kata dakwah mencakup orang yang mengajak (da'i), orang yang diajak (mad'u), pekerjaan mengajak (ajakan), isi ajakan (pesan), tujuan ajakan, media yang digunakan serta efek ajakan. Dalam al-Qur'an kata dasar da'awa dalam berbagai bentuknya 
116 HIKMAH, Volume 12 Nomor 1, Juni 2018, h. 111-131

berjumlah 213 kata. $^{5}$ Komponen Dakwah tersebut dikemukakan secara ringkas sebagai berikut:

a. $D a{ }^{\prime} i$

Beberapa defenisi da'i:

1) $D a{ }^{\prime} i$ adalah penyampai dakwah (muballigh).

2) Pengajar (mu'allim).

3) Pelopor penerapan ajaran Islam (as-Sa'i ila tathbiqihi).

4) $D a{ }^{\prime} i$ adalah penyuluh dan pembimbing (musyrif).

5) Konselor (mursyid).

6) Pendidik (murabbiy).

Da'i secara etimologis berasal dari Bahasa Arab, bentuk isim fa'il dari kata $d a$ 'a artinya orang yang melakukan dakwah. Secara terminologis, da'i adalah muslim yang baligh, berakal, memiliki ilmu pengetahuan dan berkewajiban menyampaikan dakwah kepada mad'u. ${ }^{6}$

Dari segi kualifikasinya, da'i terbagi tiga tingkatan:

1) Da'i mujtahid, yaitu da'i yang berkemampuan mengambil hukum dari alQur'an dan al-Hadis dan menjadi imam mujtahid yang diikuti oleh ummat Islam. Tingkat inilah da'i yang tertinggi kemampuannya.

2) Da'i muttabi', memahami al-Qur'an dan al-Hadis dan ilmu-ilmu Islam dengan cara belajar mempelajarinya, baik melalui guru atau melalui bukubuku. Golongan ini termasuk da'i yang profesional.

3) Da'i muqollid, yaitu orang yang turut berdakwah dengan cara ajakan kepada Islam dengan bekal ilmu yang diperoleh dari mendengar dan belajar dari para guru, mereka orang yang ta'at dan berakhlak mulia. Da'i ini termasuk orang kebanyakan secara umum ada di masyarakat. ${ }^{7}$

Sifat-sifat yang dimiliki da'i antara lain adalah:

a. Memiliki keimanan yang kuat terhadap kebenaran dakwah.

\footnotetext{
${ }^{5}$ Muhammad Fuad Abul Baqi, Al-Mu'jam al-Mufahrasu Li al-Fazhil Qur'an, (Indonesia: Maktabah Dahlan tt.) h. 326-330.

${ }^{6}$ Wahidin Saputra, Pengantar Ilmu Dakwah, (Jakarta: PT. Raja Grafindo Persada,2011) h. 261

${ }^{7}$ Moh. Ali Aziz, Ilmu Dakwah, (Jakarta: Pranada Media, 2004) h. 45.
} 
b. Memiliki hubungan yang erat dengan Allah, bersifat ikhlas, memperbanyak ibadah dan zikir.

c. Memiliki rasa tanggung jawab dalam mengemban tugas menyampaikan dakwah.

d. Memiliki wawasan yang benar tentang dakwah.

e. Mengamalkan ilmu, memiliki kesadaran tentang kewajiban dakwah.

f. Mengenali kondisi dan situasi mad'u, baik psikologis, sosiologis serta antropologisnya.

Dengan demikian dapat dikemkakan bahwa da'i adalah orang yang beriman, memiliki ilmu pengetahuan, berakhlak mulia serta memiliki rasa tanggung jawab dalam menlaksanakan kewajibannya melaksanakan dakwah. Allah menjelaskan bahwa profesi makhluk yang paling mulia adalah da'i. Firman Allah dalam surat An-Nisa' (6) 165.

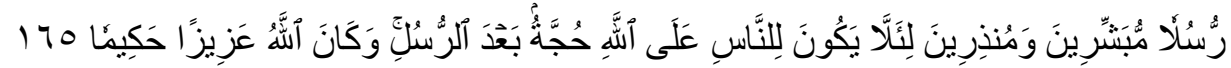

“(Mereka Kami utus) selaku Rasul-rasul pembawa berita gembira dan pemberi peringatan agar supaya tidak ada alasan bagi manusia membantah Allah sesudah diutusnya Rasul-rasul itu. dan adalah Allah Maha Perkasa lagi Maha Bijaksana. ${ }^{8}$

\section{b. Mad'u}

Mad'u adalah orang yang ditujukan kepadanya dakwah. Mad'u adalah isim maf'ul dari kata kerja $d a^{\prime} a$ artinya orang yang diajak, diseru atau di panggil. Mad'u dimulai dari yang paling dekat, yaitu diri sendiri, kemudian orang lain, yaitu terdiri dari beberapa golongan:

1) Dari segi hubungan keluarga: mad'u keluarga dekat dan keluarga jauh.

2) Dari segi letak wilayah: mad'u tetangga, teman se-lingkungan, se- kelurahan, se- daerah, mad'u se negara dan mad'u luar negeri.

3) Dari segi teologi: mad'u muslim, munafik, kafir atau non muslim.

4) Dari segi profesinya: mad'u petani, pedagang, buruh, seniman, pegawai.

\footnotetext{
${ }^{8}$ Departemen Agama RI. Al-Qur'an Dan Terjemahnya, (Jakarta: CV. Diponegoro, 2005) h.
} 83. 
5) Dari segi pendidikannya: orang awam, pelajar, mahasiswa, sarjana dan ilmuan.

Mad'u dari tingkat penerimaannya terhadap dakwah :

1) Kelompok yang dzalimun li nafsihi, yaitu orang fasik.

2) Kelompok muqtashidun, yaitu orang yang lemah imannya dan jatuh bangun dalam kehidupan.

3) Kelompok sabiquna bil khoirot, mereka yang beriman dan bertakwa. ${ }^{9}$

Mad'u terdiri dari individu, kelompok, ummat atau masyarakat pada umumnya. Mereka mempunyai hak untuk didakwahi, diajak, dipanggil, dinasehati dan dibimbing ke jalan yang benar sesuai dengan ajaran Islam. Ummat yang menjadi mad'u terbagi dua, yaitu:

Pertama: “Ummah al-Istijabah”, yaitu ummah al-Istijabah atau yang sudah meneriman dakwah. Mereka terdiri dari orang fasik, lemah iman dan orang yang bertakwa. Kedua: "Ummah ad-Dakwah”, mereka adalah orang-orang yang belum mendapat hidayah Allah untuk masuk Islam, diantara mereka ada yang ateis, musyrik, ahli kitab, kafir dan munafik. ${ }^{10}$

Adapun kewajiban mad'u adalah merespon ajakan para da'i serta mengamalkan nasehat-nasehatnya dengan mengatakan "Sami'na wa atha'na". Adapun orang-orang kafir yang tidak merespon secara positif ajakan da'i mengatakan "Sami'na wa 'ashaina”.

Materi dakwah yang disampaikan da'i kepada mad'u adalah sejumlah ilmu yang tergabung dalam beberapa disiplin ilmu-ilmu Islam seperti tafsir, hadis, tauhid, fikih, hukum, akhlak, tasawuf, sejarah dan sebagainya. Firman Allah : "Balligh ma unzila ilaika min robboika" artinya : "sampaikanlah apa-apa saja yang diturunkan Allah kepadamu”. (QS. 5 : 68).

Pada dasarnya tujuan dakwah adalah sama dengan tujuan diturunkan alQur'an kepada manusia, yaitu “yakhrujun nasa minaz- zhulumati ilan nur" (mengeluarkan manusia dari kezaliman kepada cahaya atau petunjuk) (Q.S. 33: 43), Rahmatan lil 'alamin (sebagai rahmat bagi sekalian alam), beriman kepada rukun iman (Q.S. 2: 136), mengamalkan rukun Islam (Q.S.22 : 40), berbuat ihsan

\footnotetext{
${ }^{9}$ Ibnu Katsir, Tafsir al-Qur'an al-'Azhim, (Beirut: Darul Fikri, 1997) III. H. 577.

${ }^{10}$ Tentang ateis dilihat dalam Q.S. Al-Mukminun :37.
} 
(Q.S. 28: 77), bermu'amalah sesuai syari'ah (Q.S. 9: 105), menggapai ridho Allah (Q.S. 2: 207), bahagia dunia dan akhirat (Q.S. 2 :201).

Dari tujuan trersebut dapat dikemukakan bahwa dakwah berusaha meningkatkan keagamaan masyarakat mencakup kecerdasan spritual (Iman dan Islam), kecerdasan intelektual (ilmu pengetahuan dan keterampilan) dan kecerdasan sosial (mu'amalah, ihsan dan akhlakul karimah).

\section{Pengertian dan Jenis-Jenis Hidayah}

Kata hidayah berasal dari kata bahasa Arab hadaa - yahdiy - hadyun, hudan dan hidayatan. Hidayah menurut etimologi berarti petunjuk. Lawan katanya adalah dhalalah berarti kesesatan. Secara terminologi hidayah adalah penjelasan dan petunjuk jalan yag akan menyampaikan kepada tujuan sehingga meraih kemenangan disisi Allah Firman Allah dalam surat al-Baqarah (2) ayat 5.

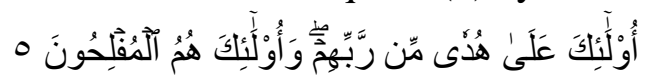

"Mereka itulah yang tetap mendapat petunjuk dari Tuhan mereka, dan merekalah orang-orang yang beruntung". 11

Orang yang beruntung ialah orang-orang yang mendapat apa-apa yang dimohonkannya kepada Allah sesudah mengusahakannya. Firman Allah dalam surat al-A'rof (7) ayat 178

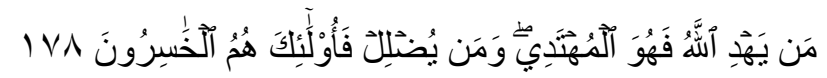

"Barangsiapa yang diberi petunjuk oleh Allah, Maka Dialah yang mendapat petunjuk; dan Barangsiapa yang disesatkan Allah, Maka merekalah orang-orang yang merugi". ${ }^{2}$

Disesatkan Allah berarti bahwa orang itu sesat berhubung keingkarannya dan tidak mau memahami petunjuk-petunjuk Allah. dalam ayat ini, karena mereka itu ingkar dan tidak mau memahami apa sebabnya Allah menjadikan nyamuk sebagai perumpamaan, Maka mereka itu menjadi sesat. Imam Ibnul Qoyyim memaparkan bawa manusia sangat membutuhkan hidayah dalam setiap waktu

${ }^{11}$ Departemen Agama RI. Al-Qur'an Dan Terjemahnya, (Jakarta: CV. Diponegoro, 2005)

h. 4 .

${ }^{12}$ Departemen Agama RI. Al-Qur'an Dan Terjemahnya, (Jakarta: CV. Diponegoro, 2005)

h. 138 
dan tarikan nafasnya dalam semua tarikan nafas yang dilakukan maupun yang ditinggalkannya, karena manusia itu berada dalam beberapa masalah yang tidak bisa diatasinya. ${ }^{13}$ As-Suyuti menjelaskan bahwa kata hidayah dan Hudan dalam al-Qur'an terdapat sebanyak 171 ayat dan terdapat pula dalam 52 hadis. Sedangkan pengertiannya dalam al-Qur'an maupun hadis terdapat 27 makna, diantaranya bermakna : penjelasan, agama Islam, pengetahuan, perintah, lurus/cerdas, rasul/ kitab, al-Qur'an, Taurat, taufik/ketepatan, menegakkan argumentasi, tauhid, mengesakan Allah, sunnah/ jalan, perbaikan, ilham/ insting, kemampuan menilai, pengajaran, karunia, mendorong, mati dalam Islam, pahala, mengingatkan, benar dan kokoh/konsisten. ${ }^{14}$

Dalam Islam, kata hidayah (Bahasa Arab: هداية (dari segi bahasa ialah "petunjuk "atau "hadiah", manakala dari segi istilah ialah petunjuk Allah ke arah kebenaran. Allah menganugerahkan hidayah kepada sesiapa yang dikehendakinya agar beriman dan mentaati perintahnya. Firman Allah dalam surat al-An'am (8) ayat 125.

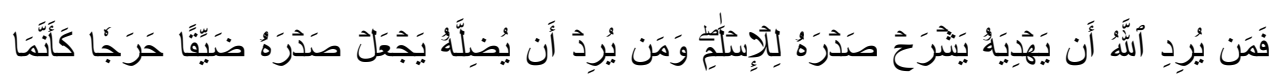

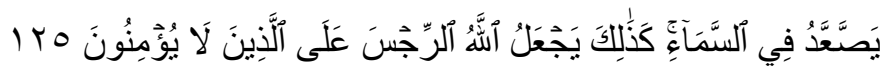

"Barangsiapa yang Allah menghendaki akan memberikan kepadanya petunjuk, niscaya Dia melapangkan dadanya untuk (memeluk agama) Islam. dan Barangsiapa yang dikehendaki Allah kesesatannya, niscaya Allah menjadikan dadanya sesak lagi sempit, seolah-olah ia sedang mendaki langit. Begitulah Allah menimpakan siksa kepada orang-orang yang tidak beriman". 15

Disesatkan Allah berarti bahwa orang itu sesat berhubung keingkarannya dan tidak mau memahami petunjuk-petunjuk Allah. dalam ayat ini, karena mereka itu ingkar dan tidak mau memahami apa sebabnya Allah menjadikan nyamuk sebagai perumpamaan, Maka mereka itu menjadi sesat. Hidayah diartikan juga

\footnotetext{
${ }^{13}$ Ibnul Qoyyim al-Jauziyah, Kitab “Al Fawa-id , (Kairo: Muassasah ummil Qura, 1424 H) h. 133

${ }^{14}$ As-Suyutiy, Al-Itqon, (Beirut: Dar ats-Tsaqofah), tt. h. 39

${ }^{15}$ Departemen Agama RI. Al-Qur'an Dan Terjemahnya, (Jakarta: CV. Diponegoro 2005) h. 
dengan rasyad (bimbingan) dan dalaalah artinya dalil atau petunjuk. ${ }^{16}$ Ibn `Âsyur menjelaskan bahwa hidayah ditandai dengan adanya ketenangan karena adanya kebaikan (khair ). Hakikat hidayah adalah al-wu șūl ilā makān al -maṭlūb (sampai pada tujuan). Menurut istilah syariat hidayah adalah ad-dilālah ‘alā mā yarḍallah min fi'l al-khair wa yuqābiluhā ạ̣-ḍalālah wa hiya tagrīr (petunjuk terhadap apa yang diridhai Allah swt dengan cara mengerjakan kebaikan dan menghindari kesesatan). Kemudian, ia mengklasifikasikan hidayah dalam empat tingkatan, yaitu: 1) potensi penggerak dan tahu, 2) petunjuk yang berkaitan dengan dalil untuk membedakan antara yang haq dan batil, 3) hidayah yang tidak dapat dijangkau akal, diutuslah rasul, dan 4) hidayah tersingkapnya hakikat rahasia yang tertinggi serta aneka rahasia. ${ }^{17}$

Jika diperhatikan urgensi hidayah dalam kehidupan, ummat Islam diwajibkan berdo'a memohon petunjuk dan hidayah sebanyak roka'at shalat, yaitu dalam surat al-Fatihah : "Ihdinash-shiraatal mustaqiem" sebanyak 17 kali dan bacaan duduk diantara dua sujud ; "wahdiniy” 17 kali, jumlah 34 kali sehari semalam. Ditambah 1 kali dalam do'a Qunut Shubuh, Allohummah di nifi man hadayta.

Ibnul Qoyyim selanjutnya memaparkan makna hidayah secara syar'i dengan membaginya kepada empat macam, yaitu:

a. Hidayah 'Ammah

Yaitu hidayah yanng bersifat umum yang diberikan kepada seluruh makhluk. Hidayah ini bersifat naluriah, termasuk panca indera untuk bisa hidup, akal, insting, fitrah dan kalbu. Firman Allah dalam surat Thaha ayat 50.

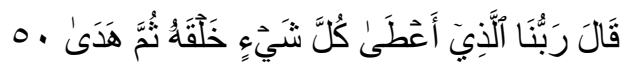

"Musa berkata: "Tuhan Kami ialah (Tuhan) yang telah memberikan kepada tiap-tiap sesuatu bentuk kejadiannya, kemudian memberinya petunjuk". 18

\section{b. Hidayah Dalaalah}

\footnotetext{
${ }^{16}$ Kamus al-Muhith, (Beirut: Dar at-Turats) h. 1733

${ }^{17}$ Muhammad Ṭahir ibn `Āsyur, Tafsīr at -Taḥīir wa at -Tanwīr , (Tunisia:Dār atTunisiyahwa an-Nasyr, 1984), jilid I, h. 187.

${ }^{18}$ Maksud hidayah 'ammah dalam hal ini adalah Allah memberikan akal, instink (naluri) dan kodrat alamiyah untuk kelanjutan hidupnya masing-masing. Hidayah ini diberikan Allah kepada seluruh manusia dan bahkan hewan. Hidayah ini menjadi washilah bagi manusia untuk memperoleh keimanan dan ketakwaan.
} 
Yaitu berupa penjelasan tentang kebaikan dan keburukan, kebaikan membawa kepada kebahagiaan dan keburukan yang membawa penderitaan. Dan tidak semua manuisa mengikuti jalan kebaikan. Hidayah dalaalah ini disebut juga al-irsyad. Firman Allah dalam surat Fushshilat ayat 17. Hidayah inilah yang bisa dilaksanakan oleh manusia dalam memberikan dakwah, yakni menjelaskan kebenaran serta menghindarkan manusia dari jalan kesesatan sekalipun hidayah yang paling sempurna, yaitu taufik yang hanya ada di tangan Allah swt. tentunya hidayah inilah sebagai jalan untuk dapat mencapai kebahagiaan manusia dengan harapan mendapat taufik dari Allah swt. Q.S. Asy-Syuura ayat 52.

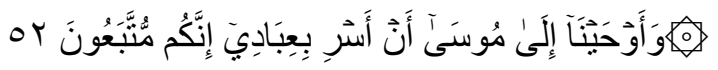

"Dan demikianlah Kami wahyukan kepadamu wahyu (Al Quran) dengan perintah kami, sebelumnya kamu tidaklah mengetahui apakah Al kitab (Al Quran) dan tidak pula mengetahui apakah iman itu, tetapi Kami menjadikan Al Quran itu cahaya, yang Kami tunjuki dengan dia siapa yang Kami kehendaki di antara hamba-hamba kami. dan Sesungguhnya kamu benar- benar memberi petunjuk kepada jalan yang lurus.

Para Rasul dan pendakwah hanya memberi petunjuk ilmu (dalaalah wal irsyad) dan agama yang benar. Firman Allah dalam surat Al-Fath (26) ayat 28:

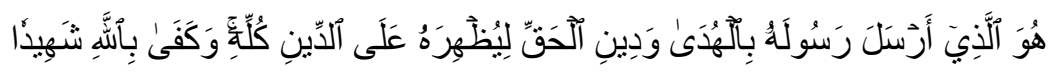

"Dia-lah yang mengutus Rasul-Nya dengan membawa petunjuk dan agama yang hak agar dimenangkan-Nya terhadap semua agama. dan cukuplah Allah sebagai saksi". ${ }^{19}$

Para ulama Ahli Tafsir menafsirkan al-huda (petunjuk) dalam ayat ini dengan ilmu yang bermanfaat dan dinul haq (agama yang benar) dengan amal shaleh. ${ }^{20}$ Maka para da'i berupaya mengajak, menyeru, membimbing, mengajari, mendidik serta menghindari manusia dari kekafiran, kemusyrikan dan kemunafikan untuk mencapai iman dan takwa serta keselamatan duania dan akhirat. Hidayah ini bersumber dari al-Qur'an dan al-Hadis, sehingga melahirkan ilmu-ilmu Islam seperti Tauhid, fikih, akhlak, sejarah dan sebagainya. Para da’i

${ }^{19}$ Departemen Agama RI, Al-Qur'an Dan Terjemahnya, (Jakarta: CV. Diponegoro, 2005) h. 411.

${ }^{20}$ Ibnu Katsir, Tafsir Ibnu Katsir, (4/209) dan Taisiirul Kariimir Rahmaan h.. 335 
berusaha menanamkan akidah, mengajarkan fikih, membimbing akhlak karimah berdasarkan petunjuk Allah dalm al-Qur'an dan Sunnah.

c. Hidayah Taufik

Yaitu ilham dalam hati manusia untuk mengikuti jalan yang benar serta kelapangan dada untuk menerima kebenaran serta memilihnya, hidayah ini disebut juga dengan hidayah ma'unah. Bila hidayah ini diberikan Tuhan kepada non muslim, maka terjadilah conversi agama, ia akan masuk Islam, bagi seorang muslim akan semakin bertambah iman dan ketakwaannya. Inilah hidayah sempurna yang mesti menjadikan orang yang meraihnya akan mengikuti petunjuk Allah. (Q.S.Fathir ayat 8). Kalau hidayah 'ammah merupakan instrumen untuk menyerap hidayah dalaalah wal irsyad, maka tujuannya tidak lain adalah untuk mencapai hidayah ma'unah Allah berupa iman, Islam dan ihsan. Dengan memperoleh tiga bentuk hidayah inilah manusia akan sampai kepada pucak hidayah jannah yaitu syurga.

Makna taufik ialah kesesuaian antara dua hal, kemudian maknanya berkembang menjadi kesesuaian antara keinginan (kehendak manusia dengan kehendak Allah. Contohnya ketika suami istri yang sedang konflik berkehendak untuk baik kembali, lalu mereka berupaya melalui mediasi antara kedua belah pihak, maka Allah akan memberi taufik kebaikan kepada keduanya. (Q.S. AnNisa' ayat 35). Contoh lain ialah keinginan nabi Syu'aib AS. akan kebaikan ummatnya melalui ikhtiar semaksimal mungkin. (Q.S.Hud ayat 87-88). Mencermati kedua ayat tersebut dapat menjadi petunjuk bahwa taufik itu timbul karena adanya iradah dan kasbu (keinginan dan usaha) dari manusia, sehingga Allah memberikan inayah dan taufik-Nya. Dengan kata lain, manusia yang tidak lalai memfungsikan hidayah 'ammah dan hidayah dalaalah Tuhan dalam terwujudnya kehendak kepada kebahagiaan dunia dan akhirat, maka Allah akan memberikan taufik dan inayahnya kepada keimanan dan ketakwaan. ${ }^{21}$

\section{d. Hidayah Jannah}

\footnotetext{
${ }^{21}$ Rosidin, Tafsir Al-Qur'an Tematik: Taufik Hidayah dan Inayah, http://uuwdialogilmu.com 1 November 2017.
} 
Yaitu diperolehnya syurga dan terhindarnya dari api neraka. (Q.S. AlA'rof ayat 43). Syaikhul Ibnu Taimiyah selanjutnya menjelaskan bahwa hamba kebutuhannya sangat mendesak terhadap kandungan do'a dalam ayat ini “Ihdina shshirotol mustaqiem", karena sesungguhnya tidak ada keselamatan dari siksa dan pencapaian kebahagiaan yang abadi di syurga kecuali dengan hidayah dari Allah. Maka barang siapa yang tidak mendapat hidayah dari Allah ini berarti dia termasuk orang-orang yang dimurkai Allah sepeti orang-orang Yahudi an Nashrani. $^{22}$

M. Quraish Shihab mengelompokkan hidayah ke dalam empat bentuk, yaitu: 1) hidayah dalam bentuk naluri, 2) hidayah dalam bentuk indera manusia, 3) hidayah dalam bentuk akal dan 4) hidayah dalam bentuk agama. ${ }^{23}$ Pendapat ini pada prinsifnya tidak berbeda dengan pembagian hidayah di atas, hanya saja hidayah pertama, kedua dan ketiga disini merupakan rincian dari hidayah umum pada pendapat di atas. Sedangkan hidayah keempat, yaitu hidayah dalam bentuk agama telah mencakup hidayah dalaalah, hidayah ma'unah serta hidayah syurga dalam pendapat di atas.

\section{Hidayah dan Keberhasilan Dakwah}

Sumber hidayah taufik dan inayah hanyalah Allah SWT. oleh karena itu seorang hamba dapat berusaha untuk mencapainya melalui do'a kepada Yang Maha Kuasa supaya dikaruniai taufik dan hidayah-Nya. Para nabi dan da'i diperintahkan Allah untuk berdakwah menyampaikan hidayah petunjuk (dalaalah wal irsyad) kepada ummat manusia. Firman Allah dalam surat al-Ma'idah (5) ayat 67:



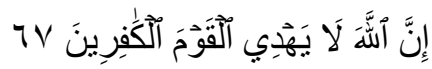

"Hai rasul, sampaikanlah apa yang diturunkan kepadamu dari Tuhanmu. dan jika tidak kamu kerjakan (apa yang diperintahkan itu, berarti) kamu tidak menyampaikan amanat-Nya. Allah memelihara kamu dari

\footnotetext{
${ }^{22}$ Ibnu Taimiyah, Majmaul Fatawa, (Lebanon: Dar al-Ma'arif14/37

${ }^{23}$ M. Quraish Shihab, Tafsir Al-Mishbah, (Jakarta: Lentera Hati, 2009) vol. 1, h. 74
} 
(gangguan) manusia. Sesungguhnya Allah tidak memberi petunjuk kepada orang-orang yang kafir". ${ }^{24}$

Nabi dan Rasul wajib berdakwah dengan cara mengajak dan menyampaikan risalah kepada manusia, nabi dan para pendakwah hanya berkewajiban menyampaikan saja, sementara hasilnya tergantung kepada hidayah taufik (ma'unah) Allah. Beberapa kisah dakwah para nabi menunjukkan bahwa mereka tidak bisa memberi hidayah ma'unah.

a. Nabi Muhammad SAW. dengan pamannya Abu Thalib. Firman Allah dalam surat al-Qashash (28) ayat 56.

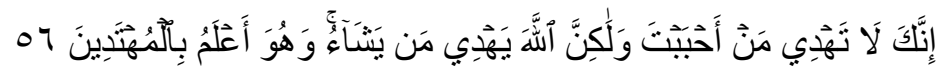

"Sesungguhnya kamu tidak akan dapat memberi petunjuk kepada orang yang kamu kasihi, tetapi Allah memberi petunjuk kepada orang yang dikehendaki-Nya, dan Allah lebih mengetahui orang-orang yang mau menerima petunjuk".

Ibnu Katsir menafsirkan ayat ini, "Allah mengetahui siapa saja dari hamba-Nya yang layak mendapatkan hidayah taufik, dan siapa saja yang tidak pantas mendapatkannya”. Syaikh Muhammad Ibnu Shalih Al-Utsaimin menerangkan, "Hidayah di sini maknanya adalah hidayah petunjuk dan taufik. Allah Subhanahu wa Ta'ala berikan hidayah ini kepada orang yang pantas mendapatkannya, karena segala sesuatu yang dikaitkan dengan kehendak Allah Subhanahu wa Ta'ala, maka mesti mengikuti hikmah-Nya." ${ }^{, 25}$ Ini berarti bahwa para nabi dan da'i tidak dapat mengetahui siapa diantara manusia yang pantas mendapat taufik hidayah taufik, mereka hanya bisa memberikan petunjuk dalalah saja.

Sebab turunnya surat al-Qashash ayat 56 ayat di atas berkaitan dengan meninggalnya Abu Thalib dalam keadaan tetap memeluk agama Abdul Muththalib (musyrik). Hal ini sebagaimana ditunjukkan hadits yang diriwayatkan dalam Shahih Al Bukhari dan Shahih Muslim, dari Ibnu Al Musayyab, bahwa bapaknya (Al Musayyab) berkata: 'Tatkala Abu Thalib akan meninggal,

\footnotetext{
${ }^{24}$ Departemen Agama RI, Al-Qur'an Dan Terjemahnya, (Jakarta: CV. Diponegoro , 2005)
} h. 95.

${ }^{25}$ Ibnu Katsir, Tafsir Al-Qur'an Al-Karim. (Mesir: Dar Ibnu Jauzi Cetakan pertama, 1431 H.) h. 321 
Rasulullah SAW. bergegas mendatanginya. Dan saat itu, 'Abdullah bin Abu Umayyah serta Abu Jahal berada di sisinya. Beliau Shallallahu 'alaihi wa sallam berkata kepadanya: "Wahai, pamanku. Ucapkanlah la ilaha illallah; suatu kalimat yang dapat aku jadikan pembelaan untukmu di hadapan Allah,'. Akan tetapi, 'Abdullah bin Abu Umayyah dan Abu Jahal menimpali dengan ucapan : 'Apakah engkau (Abu Thalib) membenci agama Abdul Muththalib?'. Lalu Nabi SAW. mengulangi sabdanya lagi. Namun mereka berdua pun mengulang kata-katanya itu. Maka akhir kata yang diucapkannya, bahwa dia masih tetap di atas agama Abdul Muththalib dan enggan mengucapkan La ilaha illallah. Kemudian Nabi SAW. bersabda: "Sungguh, akan aku mintakan ampunan untukmu, selama aku tidak dilarang, ${ }^{26}$. Lalu Allah menurunkan firman-Nya dalam surat at-Taubah (9) ayat $113 .^{27}$



"Tiadalah sepatutnya bagi Nabi dan orang-orang yang beriman memintakan ampun (kepada Allah) bagi orang-orang musyrik, walaupun orang-orang musyrik itu adalah kaum Kerabat (Nya), sesudah jelas bagi mereka, bahwasanya orang-orang musyrik itu adalah penghuni neraka jahanam". 28

b. Nabi Nuh AS. beserta anak-anaknya

Setiap rasul berupaya dengan segala daya untuk berdakwah dan mengajak manusia kepada jalan Allah. Di antara buktinya dapat kita lihat dalam surat Nuh yang menggambarkan upaya keras Nabi Allah ini selama 950 tahun. Dia menyeru kaumnya pada siang dan malam hari dengan sembunyi-sembunyi dan terangterangan, menggunakan segala cara targhib dan tarhib dengan janji dan ancaman, terus menerus membuka akal pikiran kaumnya dan mengarahkannya kepada ayat-

\footnotetext{
${ }^{26}$ Syaikh Abdurrahman bin Hasan Alu Asy Syaikh. Fathul Majid, Syarh Kitab At Tauhid, (Lebanon, Dar at-Tauhid,tt.) h. 345

${ }^{27}$ Syaikh Abdurrahman bin Hasan Alu, Fathul Majid, Syarh Kitab At Tauhid, (Mesir: Dar Maktabah tt.) h. 210. Ibnu Katsir mengemukakan bahwa dalam riwayat Ibu Mas'ud sebab turun surat at-Taubah ayat 113 ini ialah ketika nabi SAW dibolehkan berziarah ke makam ibunya Aminah, tetapi dengan turunnya ayat ini, maka nabi tidak diizinkan mendo'akannya karena masih dalam kemusyrikan. Tafsir Al-Qur'anul Karim, (Beirut: Dar al-Fikri), 1985

${ }^{28}$ Departemen Agama RI. Al-Qur'an Dan Terjemahnya, (Jakarta: CV. Diponegoro , 2005) h. 163.
} 
ayat Allah di seluruh jagad raya tetapi manusia selalu menolaknya. Dalam surat Nuh ayat 21, "Nuh berkata: Ya Tuhanku, sesungguhnya mereka telah mendurhakaiku dan telah mengikuti orang-orang yang harta dan anak-anaknya tidak menambah kepadanya selain kerugian belaka”. Dalam surat Hud ayat 42-43 dijelaskan bahwa ketika Nuh melihat anaknya yang tenggelam, Nabi Nuh berdo'a (yang artinya), "Dan Nuh pun menyeru Rabbnya, 'Wahai Rabbku, sesungguhnya anakku termasuk keluargaku, dan sesungguhnya janji-Mu adalah janji yang benar, dan Engkau adalah Hakim yang seadil-adilnya.' Allah berfirman, 'Wahai Nuh, sesungguhnya dia bukan termasuk keluargamu (yang diselamatkan), sesungguhnya amalannya bukanlah amalan yang shalih. Maka janganlah engkau meminta kepada-Ku sesuatu yang tidak engkau ketahui. Sesungguhnya Aku peringatkan engkau agar jangan termasuk orang-orang yang jahil."

c. Para Rasul Allah dengan Bani Israil

Dalam surat Yaasien dijelaskan bahwa Bani Israil telah mendustakan para Rasul Allah. Ketika Allah mengutus dua orang Raul, mereka mendustakannya, lalu Allah mengutus yang ketiga, tetapi mereka tetap menolaknya. Firman Allah dalam surat Yaasien (22) ayat 17.



"Dan kewajiban Kami tidak lain hanyalah menyampaikan (perintah Allah) dengan jelas". ${ }^{29}$

Ayat ini menunjukkan bahwa para rasul hanya bisa memberikan petunjuk dan ajakan kepada tauhid dan menghindarkan Bani Israil dari kemusyrikan, namun Allah belum memberikan hiayah taufiknya kepada mereka, sehingga mereka selalu mendustakan para Rasul yang diutus Allah kepada mereka dan mereka tetap dalam kesesatan. Syaikh 'Abdurrahman bin Nashir AsSa'di rahimahullah menjelaskan permisalan suatu negeri yang diutus dua orang utusan (rasul). Mereka berdakwah untuk mengajak manusia supaya bisa beribadah pada Allah semata dan mengikhlaskan ibadah pada-Nya. Mereka pun berdakwah

\footnotetext{
${ }^{29}$ Departemen Agama RI, Al-Qur'an Dan Terjemahnya, (Jakarta: CV. Diponegoro, 2005)
} h. 352 . 
untuk melarang dari kesyirikan dan maksiat. ${ }^{30}$ Ada dua orang yang telah diutus, lalu diutus lagi rasul yang ketiga, jadilah ada tiga utusan. Tetap saja dakwah ditolak. Malah kaum yang didakwahi berkata, "Kami juga manusia semisal kalian." Maksud mereka, apa yang membuat para rasul lebih unggul daripada mereka, padahal sama-sama rasul juga manusia. Demikian juga dakwah nabi Musa AS. kepada Fir'aun yang tidak diberikan Allah hidayah kepadanya sampai ajalnya tiba.(Q.S. Thaha), dan istri nabi Luth sebagai orang yang dicintainya menjadi seorang musyrik yang tidak mendapat hidayah dari Allah swt.

Uraian tersebut menunjukkan bahwa hidayah hanyalah milik Allah, dan Allah memberi hidayah kepada orang yang dikehendakinya. Barangsiapa yang Allah beri hidayah, tidak ada seorang pun yang bisa menyesatkannya dan barangsiapa yang telah Allah sesatkan, tidak ada seorang pun yang bisa memberi hidayah kepadanya. Allah berfirman yang artinya "Allah memberikan hidayah kepada siapa yang dikehendaki-Nya kepada jalan yang lurus.” (QS. Al-Baqarah: 213) dan Allah berfirman yang artinya "Dan barangsiapa yang disesatkan Allah, niscaya tak ada baginya seorang pemberi petunjuk.” (QS. Az-zumar:23).

Kasus konversi agama (religious conversion) merupakan bukti berlakunya hidayah. Apabila Allah memberikan hidayah bagi seseorang, maka dia akan memperoleh ma'unah iman dan takwa, tetapi sebaliknya iman dan takwa seseorang akan hilang apabila Allah mencabutnya kembali dan menggantinya dengan kesesatan. Dalam surat an-Nahlu ayat 125 dijelaskan bahwa ajakan para da'i hendaknya dengan penuh hikmah, melalui pengajaran yang baik dan benar serta cara debat yang lebih baik pula. Hal ini dikarenakan Allah pada prinsifnya telah lebih mengetahui siapa diantara hamba-Nya yang sesat dan siapa pula yang mendapat hidayah.

Untuk itulah da'i yang bertugas memberikan hidayah dalaalah wal irsyad berusaha membimbing mad'u supaya: 1) Bertaubat dan bertauhid, 2) Belajar alQur'an dan Sunnah nabi saw. 3) Beribadah kepada Allah swt. dan berdo'a serta mendo'akan mad'unya supaya selalu beroleh taufik hidayah dan ma'unah. 4)

\footnotetext{
${ }^{30}$ Syaikh 'Abdurrahman bin Nashir As-Sa'di, Tafsir As-Sa'di (Taisir Al-Karim Ar-
} Rahman). (Penerbit Muassasah Ar-Risalah, Cetakan kedua, 1433 H.) h. 734-735. 
Menta'ati perintah Allah dan rasul-Nya serta menghindari larangan-Nya. 5) Bertawakkal dan ridlo terhadap takdir Allah. Ini dapat ditempuhdengan berbagai metode antara lain: ceramah, tulisan, bimbingan dan konseling serta melalui keteladanan.

Dengan demikian terdapat hubungan yang sinergi antara hidayah dan dakwah. Hubungan tersebut timbul dalam artian bahwa hidayah menjadi faktor penting kesuksesan dakwah. Hidayah 'ammah, dalaalah, ma'unah dan syurga yang dianugerahkan Tuhan menjadi faktor utama suksesnya dakwah. Demikian juga dakwah adalah sebagai salah satu media yang sangat berperan mensosialisasikan dan mengembangkan hidayah 'ammah dan hidayah dalaalah yang diberikan Tuhan, sehingga masyarakat memperoleh taufik hidayah (ma'unah) berupa iman, Islam dan ihsan demi kebahagiaan hidup di dunia dan akhirat.

\section{Kesimpulan}

Kesuksesan dakwah tidak terlepas dari beberapa faktor. Faktor hidayah yang dianugerahkan Tuhan kepada manusia termasuk salah satu faktor yang amat penting. Dari empat macam hidayah Tuhan kepada manusia, hanya hidayah dalaalah wal irsyad yang dapat diberikan nabi dan da'i kepada mansyarakat. Nabi dan da'i hanya dapat memberikan hidayah dalaalah atau irsyad, yaitu memberikan petunjuk, arahan, bimbingan, ajakan maupun seruan amar ma'ruf nahi munkar sesuai dengan ilmu-ilmu Islam yang bersumber dari al-Qur'an dan al-Hadis. Sedangkan hidayah taufik atau ma'unah iman dan takwa hanya Allah swt. yang berhak menganugerahkannya, karena hanya Dia-lah yang mengetahui siapa yang pantas mendapatkannya. Nabi dan da'i tidak mampu memberikan hidayah ma'unah tersebut kepada manusia, sekalipun kepada orang dekatnya sendiri yang dia kasihi. Orang yang sudah menerima dakwah tetapi belum bersedia masuk Islam, maka dia masih mencapai hidayah dalaalah wal irsyad, tetapi belum mendapat hidayah ma'unah dari Allah SWT. Di sisi lain dakwah berperan membawa mad'u supaya beroleh hidayah, baik dalaalah, ma'unah dan hidayah syurga. Para da'i dan ummat Islam dituntut supaya meningkatkan dakwahnya dalam mengajak masyarakat supaya bertauhid, beribadah, berakhlak 
130 HIKMAH, Volume 12 Nomor 1, Juni 2018, h. 111-131

mulia serta metaati aturan-aturan yang disyariatkan, sebagaimana agar selalu berdo'a agar memperoleh taufik dan hidayah dari Allah SWT. 


\section{Daftar Pustaka}

As-Suyutiy, Al-Itqon, dan Ibnul Qoyyim dalam Nuzhatul A'yun.

Departemen Pendidikan Dan Kebudayaan, Kamus Besar Bahasa Indonesia, Balai Pustaka Jakarta.

Ibnu Katsir, Tafsir Al-Qur'an Al-Karim. Cetakan pertama, tahun 1431 H. Dar Ibnul Jauzi.

Ibnu Taimiyah, Majmaul Fatawa, Mathabi’ al-Riyadl, 1985.

Imam Bukhari, Shahih al-Bukahary, Dar al-Fikri, Beirut, 2000.

Imam Muslim, Shahih Muslim, Dar al-Ihya' at-Turats al-Arabiy, 1955.

Moh. Ali Aziz, Ilmu Dakwah, Pranada Media Jakarta, 2004

M. Quraish Shihab, Tafsir Al-Mishbah, Lentera Hati, Jakarta 2009 vol. 1,

Muhammad Fuad Abul Baqi, Al-Mu'jam al-Mufahrasu Li al-Fazhil Qur'an, Indonesia Maktabah Dahlan.

Muḥammad Tahir ibn 'Āsyur,Tafsīr at-Tahrī̄r wa at-Tanwīr , Dār atTunisiyahwa an-Nasyr, Tunisia, 1984, jilid I

Syaikh Abdurrahman bin Hasan Alu Asy Syaikh, Fathul Majid, Syarh Kitab At Tauhid,

Syaikh 'Abdurrahman bin Nashir As-Sa'di, Tafsir As-Sa'di (Taisir Al-Karim ArRahman). Cetakan kedua, tahun 1433 H.. Penerbit Muassasah Ar-Risalah

Wahidin Saputra, Pengantar Ilmu Dakwah, PT. Raja Grafindo Persada, Jakarta, 2001. 